immunocompromised, due to exposure to agrotoxics, this population is more susceptible to COVID-19, a situation that is aggravated by workplaces and working conditions, which place them at risk, due to frequent circulation and the need for entry into residences.

Method This descriptive study was part of a multicenter research with Endemic Workers from the State of Rio de Janeiro, Brazil. To investigate the work during the pandemic we used an online questionnaire, structured with open and closed questions.

Results Preliminary results from the 140 responses to the questionnaire demonstrate that: $78 \%$ of the Endemic Workers reported diagnosed disease and from these, $70 \%$ had comorbidities. The most frequent are hypertension (49\%), diabetes $(22 \%)$, respiratory problems $(22 \%)$ and malfunction of the liver and kidneys (17\%). Although $88 \%$ did not have a diagnosis of COVID-19, 64\% reported having co-workers and/or family members with COVID-19. Regarding remote work: 2\% reported working at home, $29 \%$ were working in scale and/or alternate time and 53\% were working full time. Workers who stayed the longest time in remote work (five months) represented only $8 \%$, with $31 \%$ remaining in full time presential work during the period in which isolation and detachment measures began in Brazil.

Conclusion Protective measures of the health of these workers and assisting this population to prevent the transmission of SARS-Cov-2, are necessary to implement health protection policies, including other exposures at work, such as agrotoxics.

\section{P-432 CHEMICAL EXPOSURE TO PESTICIDES (AGROTOXICS) OF ENDEMIC WORKERS IN THE STATE OF RIO DE JANEIRO, BRAZIL}

${ }^{1}$ Ana-Paula Neves, Priscila Vidal, Victor Figueiredo, Marcus Santos, Gabriel Silveira, Luiza Dantas, Ébio-Willis Moreira, Marcos-Rogério Silva, Roberto-Paulo Nunes, Socorro Setúbal, Antônio-Carlos Cardoso, Monica Martins, Edilene Pereira, Tatiana Docile, Márcia Sarpa, Aline Gurge, Fátima Moreira, Leandro Carvalho, Luciana Gomes, MariaBlandina Santos, Isabele Costa-Amaral, Eline Gonçalves, Luiz-Cláudio Meirelles, Liliane Teixeira, Ariane Larentis, Ana-Cristina Rosa. 'Escola Nacional of Public Health Sergio Arouca (Ensp), Brazil and Oswaldo Cruz Foundation (Fiocruz), Brazil

\subsection{6/OEM-2021-EPI.324}

Introduction The Brazilian vector control is characterized by intensive use of pesticides (agrotoxics) such as organophosphates, carbamates, pyrethroids and benzoylureas. Until the 1990 s, organochlorines were also used. Some of these substances have already been banned, in other countries, but continue to be used in Brazil and are associated with several harmful health effects such as neurotoxicity and carcinogenicity. Endemic workers have been continuously exposed for decades and have a high rate of illness and death from cancer.

Objective To identify chemical exposure by agrotoxics in the work process of endemic workers in the state of Rio de Janeiro, Brazil.

Method Observational, descriptive, cross-sectional and multicenter study. 139 questionnaires answered remotely by the endemic workers in the state of Rio de Janeiro, Brazil were analyzed.

Results $61.2 \%$ worked manipulating/applying agrotoxics. $39.6 \%$ worked between 20-29 years (mean = 15.9; SD = 12.4) in direct contact with agrotoxics. $79.1 \%$ had already worked directly with agrotoxics at some point. The most commonly used agrotoxics between 2010 and 2020 were: Bacillus thuringiensis (bacterial larvicide) (40.7\%); pyriproxifem (pyridyloxypropyl ether) (42.1\%); benzoylphenylureas: diflubenzuron (35.0\%) e novaluron (25.7\%); pyrethroids cypermethrin (33.6\%), deltamethrin (12.1\%) e permethrin (9.3\%); organophosphates: malathion (33.6\%), temephos (28.6\%) e fenitrothion (16.4\%); and bendiocarb (carbamate) (9.3\%). $71.9 \%$ reported direct contact of the agrotoxics with the skin. The most used individual protection equipment (IPE) were gloves (42.9\%), boots (31.4\%) and overalls (17.9\%). 47.5\% did not use or received IPE from employer. $53.2 \%$ of workers didn't have training and $43.9 \%$ of those who did, didn't consider it sufficient. $98.6 \%$ washed work clothes at home. $69.8 \%$ reported symptoms of intoxication after contact with agrotoxics (skin irritation, burning in the nose and mouth, difficulty breathing, vomiting or diarrhea, weakness, headache, nausea, fainting).

Conclusion Endemic workers have been exposed acutely and chronically for decades to various agrotoxics. Changes in the work process and chemical-dependent vector control are required.

\section{P-434 'NIGHT WORK: RELATIONSHIP WITH THE RISK OF DEVELOPMENT OF DM, CARDIOVASCULAR DISEASES IN HEALTH WORKERS.'}

${ }^{1}$ Marita Asmat Inostrosa. ${ }^{1}$ Hospital de Leon, Spain

\subsection{6/OEM-2021-EPI.325}

Introduction Shift work has become essential to our modern 24-hour society. While night workers have been found to experience an increased risk of cardiometabolic diseases, such as diabetes mellitus (DM) and cardiovascular disease (CVD). Conceptual hypothesis: The night shift reduces melatonin levels and increases the risk of type II DM and cardiovascular diseases in health workers in a hospital.

Objective To analyze the association between low melatonin levels and increased risk of DM and cardiovascular diseases, and night shift in workers of a hospital.

Methods We used an analytical, longitudinal, retrospective study over a 5-year follow-up of a cohort in which the results of workers suffering from DM and cardiovascular diseases are compared in two groups: a) One group, exposed to night shifts, and b) a second group, not exposed to night shifts. The population of this study will be made up of health workers who voluntarily attend health examinations (ES) of the Occupational Service of Hospital from January 1, 2009 to December 31, 2019, incuding the apparently healthy and labor-active working population, between the ages of 19 and 65 .

Results and conclusion are forthcoming

\section{P-435 MORBIDITY AND MORTALITY OF WORKERS IN THE VECTOR CONTROL OF THE STATE OF RIO DE JANEIRO, BRAZIL}

${ }^{1}$ Victor Figueiredo, Marcus Santos, Gabriel Silveira, Ana-Paula Neves, Priscila Vidal, Marcos Rogério Silva, ébio-Willis Moreira, Roberto-Paulo Nunes, Socorro Setúbal, Luiza Dantas, Antônio-Carlos Cardoso, Mônica Martins, Fátima Moreira, Ana-Cristina Rosa. 'Fiocruz, Brazil

\subsection{6/OEM-2021-EPI.326}

Introduction Brazilian vector control, characterized by the intensive use of pesticides (agrotoxic), has resulted in decades 
of continuous exposure of endemic workers to these harmful substances, including organochlorines (BHC and DDT), organophosphates (temephos and malationa), carbamates (bendiocarb), pyrethroids (deltamethrin) and benzoylureas (diflubenzuron), which are associated with several deleterious health effects, such as neurotoxicity, carcinogenicity and endocrine disruption.

Objective To evaluate data on morbidity and mortality of endemic workers in the state of Rio de Janeiro, Brazil.

Methods The evaluation is part of a multicenter, observational, descriptive and cross-sectional study. 109 death certificates provided by work unions were analyzed through documentation provided by family members and data on work leave, between 1942 and 2018, by the Rio de Janeiro State Nucleus of the Ministry of Health.

Results $70.64 \%$ of workers died at a productive age (40-59 years), with an average of 54 years (SD: 9.77). The main causes of death were diseases of the circulatory system (38.7\%) and cancer (14.7\%). The number of deaths has progressively increased from around 5 annual deaths in 2010 to 40 from 2015 onwards. In addition, various types of illnesses have caused 5,024 instances of work leave.

Conclusion Considering the preliminary results, the occurrence of deaths in working age demonstrate their precocity, with a reduction of at least 20 years in life expectancy. The results show morbidity and mortality and the increase in the number of cases related to the use of agrotoxic, the precarious working conditions and the absence of work process monitoring by workers.

\section{P-436 'STUDIES OF COMMON MENTAL DISORDERS OF ENDEMIC WORKERS IN THE STATE OF RIO DE JANEIRO, BRASIL}

'Priscila Vidal, Victor Figueiredo, Marcus Santos, Gabriel Silveira, Ana Silva, Luiza Dantas, Marcos-Rogério Silva, Ébio-Willis Moreira, Roberto-Paulo Nunes, Socorro Setubal, AntônioCarlos Cardoso, Monica-Regina Martins, Dominique Marçal, Fátima Moreira, AnaCristina Rosa, Leandro Carvalho, Maria-Blandina Santos, Luiz-Claudio Meirelles, Isabele Costa-Amaral, Eline Gonçalves, Ariane Larentis, Liliane Teixeira, Luciana Gomes. ${ }^{1}$ Fiocruz National School of Public Health Sergio Arouca (Ensp)

\subsection{6/OEM-2021-EPI.327}

Introduction Endemic workers are among the categories most exposed to the effects of pesticides used in vector control. They also face unsafe working conditions with reports of bullying, inadequacy or lack of training, and almost non-existent educational processes. Previous studies have observed damage to the mental health of rural workers caused by exposure to pesticides.

Objective To analyze the relationship between mental health and the activities of workers in the fight against endemic diseases in the state of Rio de Janeiro, Brazil in the current situation.

Methods To this end, an online questionnaire was applied with questions related to work, health, sleep quality, and working and health conditions in the pandemic, including the Self-Reporting Questionnaire for screening common mental disorders (CMD). We obtained 139 valid questionnaires and employed the Chi-square and Fisher's exact test for statistical analysis.

Results The study identified the frequency of $43.2 \%$ of symptoms indicative of CMD in the studied population regarding CMD. When stratified by gender, we observed that the occurrence was almost twice more likely in males than in females $(p \leq 0.04)$. Marital status and education were also associated with $\mathrm{p} \leq 0.01$ and $\mathrm{p} \leq 0.05$, respectively. The work associations were sprinkler pump $(\mathrm{p} \leq 0.02)$, referred intoxication symptoms $(p \leq 0.00)$, and the previous diagnosis of depression $(\mathrm{p} \leq 0.00)$. Concerning cases of a previous diagnosis of depression, we identified associations with females $(\mathrm{p} \leq 0.03)$; activity involving contact, handling, or application of agrotoxic in the past $(\mathrm{p} \leq 0.04)$; referred symptoms of intoxication $(\mathrm{p} \leq 0.00)$; reported use of malathion in the last decade $(p \leq 0.02)$; activities related to field agent $(p \leq 0.05)$, and suicidal ideas $(\mathrm{p} \leq 0.00)$.

Conclusion The results reinforce that work conditions and processes have been a triggering factor for illness in the studied population. Changes in the work process are necessary to avoid work that is harmful to the worker's health.

\section{P-438 UNMASKING THE TRUTH: A LONGITUDINAL STUDY EXAMINING WORKPLACE PROTECTIVE STRATEGIES, WORKING ARRANGEMENTS, AND THEIR IMPACT ON WORKERS' HEALTH, SAFETY AND PRODUCTIVITY IN NEWFOUNDLAND AND LABRADOR DUR}

${ }^{1}$ Kim Cullen, Dianne P Ford, Amanda Butt, Sumayyah Musa. ${ }^{1}$ Memorial University of Newfoundland, Canada

\subsection{6/OEM-2021-EPI.328}

Introduction Under federal and provincial legislations, employers across Canada have a responsibility to reasonably protect the health and safety of their workforce. The COVID-19 pandemic has created many challenges for employers to meet these responsibilities. Employers have been particularly hindered in their efforts to protect their workers due to changing understandings of COVID-19 risks over time. Knowledge of effective public health measures is continuously evolving, with new evidence emerging almost daily. Workplace-led strategies have been designed and implemented to specifically protect workers from exposure to the COVID-19 virus. What we don't know is the unintended long-term consequences these workplace protection measures may be having on workers' health and ability to work safely during the pandemic.

Objectives To examine the influences of geographical region, sex and gender, industry, occupation, and perceptions of worker autonomy on the relationship between workplace-led strategies to protect workers from exposure to COVID-19 on measures of worker health safety and productivity.

Methods Using a longitudinal survey with a purposive sampling of Newfoundland and Labrador workers at regular intervals over a 12-month period, data were collected across six domains: participant demographics, pandemic-specific workplace policies and practices, working environment (including remote and on-campus work), psychosocial working conditions, physical health and mental health.

Results Findings from the baseline, 3 month and 6-month follow-up surveys will be presented. Preliminary results from this work highlight the challenges faced by workers under remote and standard work arrangements and the relationship among these working conditions and impacts on worker health, safety and productivity during the changing nature of work throughout the COVID-19 pandemic.

Conclusion The outcomes from our research will provide new knowledge through the collection of stakeholder perspectives 